\title{
O conceito saussuriano de língua: desdobramentos ${ }^{1}$
}

\author{
Norma Discini \\ Universidade de São Paulo (USP), São Paulo, São Paulo, Brasil \\ normade@uol.com.br
}

DOI: http://dx.doi.org/10.21165/el.v46i3.1741

\begin{abstract}
Resumo
A língua, concebida por Saussure como sistema de signos e como organização gramatical vinculada à faculdade da linguagem, favorece a compreensão que se tem de um mundo tecido pela própria linguagem. Por outro lado, os herdeiros do saussurismo, entre os quais está Benveniste (1995), passam a cotejar "o homem na língua" como uma enunciação sistematizada, embora a fala tenha sido concebida por Saussure como um ato individual de vontade e inteligência, que, contraposto ao sistema linguístico, não é passível de descrição. Fala regrada remete a discurso. No debate desses pontos ficarão assentadas nossas reflexões, que procurarão trazer à luz mecanismos segundo os quais toma corpo "o homem na língua", tal qual antevisto no interior de seus textos e dos seus discursos.
\end{abstract}

Palavras-chave: língua; fala; enunciação; discurso.

\section{The saussurian concept of language: developments}

\begin{abstract}
A language, conceived by Saussure as a system of signs and a grammatical organization linked to the faculty of language, favours the understanding of a world woven by language itself. On the other hand, Saussure's heirs, among whom is Benveniste (1995), describe "man in the language" as a systematized enunciation, although speech was conceived by Saussure as an individual act of will and intelligence, which, opposed to the linguistic system, cannot be described. Speech with rules refers to discourse. Our reflections will be based on the discussion of these points, which will seek to bring to light mechanisms according to which "man in the language" takes shape, just as is foreseen within Saussure's texts and speeches.
\end{abstract}

Keywords: language; speech; enunciation; discourse.

\section{Notas iniciais: língua e discurso}

Saussure concebeu a língua como um sistema. No âmbito dos estudos do discurso, essa concepção abre possibilidades de descrição das restrições semânticas, sustento tanto de uma formação discursiva, como do corpo do enunciador - o ator da enunciação engendrado a partir do tratamento imprimido num ator do enunciado (um personagem). Esses princípios dirigem nossas reflexões.

O discurso de fundação da linguística estrutural, radicado no Curso de Linguística Geral (SAUSSURE, 1970) - CLG - apresenta proposições contempladas pelas ciências humanas e, mais especificamente, pelos estudos do discurso. O pensamento de Saussure é arrimo para quem considera o mundo um enunciado tanto construído como decifrável

\footnotetext{
${ }^{1}$ Na elaboração deste ensaio, a autora foi beneficiada pela Bolsa de Pesquisador Visitante, fornecida pela Fundação de Amparo à Pesquisa do Estado de Minas Gerais (FAPEMIG), e a pesquisa foi desenvolvida junto à Universidade Federal de Uberlândia (UFU).
} 
pelo homem (GREIMAS; COURTÉS, 2008). Pensar que o signo linguístico é unidade constituída por meio da relação entre uma imagem acústica e um conceito leva a aceitar que não há conceitos dados de antemão, naquilo que parece ser a organização natural de tudo que nos cerca. O signo, no interior do sistema linguístico, classifica as coisas que "estão aí", ao nomeá-las. Além disso, para os estudos do discurso, um signo definido não como entidade em si, mas conforme um sistema de valores que compõe um todo leva a interrogar a relação das partes com o todo, e deste com elas, seja esse todo relativo ao enunciado ou à enunciação.

Também provoca mudanças nas investigações discursivas pensar uma língua, que, além de ser vista como sistema de signos, implica uma fala. Apesar de, no $C L G$, a fala estar exposta como realização individual e não estruturada, logo não passível de descrição, ela pode ser entendida como regrada, a partir do postulado de que a língua é forma (é estrutura, é sistema), não substância.

Uma fala compreendida como sistematicamente organizada, logo um fenômeno não aleatório, está nas circunvizinhanças do que Saussure postula sobre a língua. No $C L G$, língua e fala se reúnem sob o arcabouço da linguagem. Desse modo, aí se encontram a língua, "social em sua essência", e a fala, "parte individual da linguagem" (p. 27)2. Os parâmetros oferecidos por Saussure para a análise linguística são ponto de partida para a análise da fala, homologada, no avanço dos estudos linguísticos, ao discurso.

A partir do conceito saussuriano de língua somos encorajados a buscar uma fala estruturalmente organizada. Benveniste (1995), herdeiro teórico de Saussure, faz a passagem da língua para a fala homologada ao discurso. Apresentada como uma instância que reúne em si as categorias de pessoa, tempo e espaço no ato de apropriação da língua pelo falante, firma-se então a enunciação, e passamos da língua para o discurso.

A semiótica discursiva examina os sistemas em que se fincam essas categorias no âmbito da sintaxe do discurso. Mas há paralelamente a semântica discursiva, com os temas e as figuras que os particularizam; juntamente com eles, há o tratamento ético que a enunciação neles imprime. Adentramos o campo dos mecanismos de discursivização do corpo enunciativo, que é identificado nas fronteiras entre formações discursivas e nas fronteiras entre estilos, sejam os de gênero, sejam os de autor.

Sem Saussure na retaguarda, não poderíamos ter chegado à noção de uma enunciação estruturada, sintática e semanticamente. A estrutura é um "torniquete", como lembra o genebrino, mas observada na dimensão semântica do discurso, ela é simultaneamente aberta ao acontecimento. $\mathrm{O}$ externo se compõe no âmago do interno, o que não é novidade, pois está nas entrelinhas do CLG. A língua, como rede interna de relações (e de interdependências), é "uma instituição social" (p. 24) - ou é "social em sua essência" (p. 27), o que supõe que o caráter social da língua é um de seus caracteres internos. Isso vem ao encontro da noção de arbitrariedade do signo.

A arbitrariedade do signo passa por uma fenda feita na relação significantel significado, para que, por aí, adentre o exterior: as convenções sociais, que falam de distintas culturas. Diante do exterior constituinte do interior - fato que faz pensar no social como essência da língua - duas perguntas vêm à tona: A primeira é: "Como podemos nos beneficiar do pensamento teórico de Saussure para entender melhor o mundo que nos

\footnotetext{
${ }^{2}$ Sempre que possível, serão citadas apenas as páginas do $C L G$, sem a repetição da data da publicação da edição consultada, o que será feito com o objetivo de viabilizar o fluxo da leitura.
} 
cerca?". A segunda questão parte de um fato que extrapola os limites de um texto, com suas margens que o confinam nos limites de dois brancos (o antes do início e o depois do fim do conteúdo veiculado): "O $C L G$ pode ajudar a desvendar o que está além das aparências dos objetos (menos fluidos ou mais), que deslizam entre textos, discursos e práticas? - Esses objetos não encapsulados pelas margens de um texto?". Um postulado de Saussure responde a essas perguntas: é o princípio da articulação, que subjaz à ideia de forma, por sua vez sustento da noção de formação discursiva e de um corpo falante.

\section{Língua e linguagem: o princípio de articulação}

O princípio de articulação (entre as partes e o todo), no $C L G$, é estabelecido entre unidades mantidas em coerção recíproca no interior de um sistema. $\mathrm{Na}$ apropriação feita pelos estudos discursivos do $C L G$, esse princípio: a) é entendido como constitutivo não só da língua, mas também dos textos, dos discursos e das práticas; b) é condição para que se desenvolva uma análise sobre: o que está aquém da superfície textual (o significado); o que manifesta o conceito (o significante); o que está no limiar entre um texto e outro.

A articulação, antes da língua, está na linguagem. Paralelamente à definição de linguagem como faculdade de constituir uma língua conforme um sistema de signos distintos correspondentes a ideias distintas, Saussure acolhe o princípio de uma linguagem articulada. Faz isso, ao constatar que a questão do aparelho vocal se revela secundária no problema da linguagem - tendo alertado antes disso para o fato de que $o$ som não passa de um instrumento do pensamento e não existe por si mesmo. Nos domínios da língua, tal qual pensada por Saussure, nada existe por si mesmo.

Para a noção de linguagem articulada, acrescenta: "Em latim, articulus significa 'membro, parte, subdivisão numa série de coisas'; em matéria de linguagem, a articulação pode designar não só a divisão da cadeia falada em sílabas, como a subdivisão da cadeia de significações em unidades significativas" (p. 18). Apegando-se a essa noção de linguagem articulada, Saussure completa que não é a linguagem que é natural ao homem, mas a faculdade de constituir uma língua (ibid.). No âmbito da semântica discursiva, deduzimos que articular um tema a outro, uma figura a outra, uma avaliação e outra feita de um tema e de uma figura remete a papéis temáticos e configurativos desempenhados pelo enunciador. Isso é procedimento de ordenação do mundo - conforme uma ordem que está na língua e no discurso, diferentemente daquilo que se encontra no próprio mundo. Assim permite pensar uma leitura feita de Saussure, com vistas a depreender a noção de uma fala regrada: não só quanto aos sistemas de pessoa, tempo e espaço (da sintaxe discursiva), mas também quanto a um corpo enunciativo semantizado.

O princípio de articulação remete ao conceito de valor, este que emerge da relação entre termos. A relação, que estabelece o valor de uma peça num jogo de xadrez, diz respeito à articulação interna das regras de deslocamento das peças; é segundo tais regras que o valor da peça é definido - o cavalo, no jogo de xadrez, não tem um valor advindo de sua materialidade. Não importa se é feito de mármore, de madeira etc.

Qual é o valor de um tema em determinada rede conceitual estabelecida? E o valor de uma figura na rede de figuratividade - ambos, tema e figura, que fundam a coerência semântica do discurso? Para responder, temos de fazer o deslocamento da noção de sistema do âmbito da língua para o âmbito do discurso. Ao ato de apropriação da língua segundo categorias de pessoa, tempo e espaço segue a apropriação ética dos temas e 
figuras enunciados, conforme um ato predicativo de julgamento. É o ato que, realizado pela enunciação, crava-se na língua feita discurso.

Assim se projeta a noção de uma fala regrada, que engendra um discurso regulado por um sistema de restrições semânticas, o que sugere o cotejo necessário de qualquer enunciado com suas condições de produção. A partir daí vêm à luz restrições semânticas. Permeia esses mecanismos a noção de um valor que leva adiante no discurso o padrão conceitual instaurado como isotopia temática e figurativa. $O$ valor linguístico não se restringe à propriedade que tem uma palavra de "representar uma ideia" (p. 132), isso é apenas "um dos aspectos do valor" (ibid.).

Saussure diz não acreditar que valor e significação sejam palavras sinônimas (p. 133). O valor confirma o exterior no interior, na medida em que, diante da solidariedade entre todos os termos da língua, o valor de um resulta tão somente da presença simultânea de outros. Funda-se aí o olhar para a lateralidade, que, ao não levar em conta qualquer coisa em si mesma, contempla o outro no interior do que poderia parecer uno, homogêneo, fechado e acabado. Funda-se aí também o gesto não avesso ao analista do discurso, que contemplará, com o rigor do método que nasce da "descoberta" da língua como sistema, a estrutura semântica, aberta à contingência do acontecimento: a enunciação, com seu corpo semantizado. Por isso falamos em ator da enunciação. $\mathrm{O}$ valor discursivo de uma unidade da semântica, como um tema ou uma figura, não está no elenco de temas e figuras tidos como os favoritos de um discurso por serem os mais recorrentes. O tema tem de confirmar o exterior no interior. Aí está o seu valor.

\section{O valor não se confunde com o significado}

O valor já no âmbito da língua não se confunde com o significado, pois advém não de um signo fechado em si como significante/significado. É um elemento da significação e a extrapola. Logo, a significação é dependente do valor, não determinante dele. No âmbito do discurso, constatamos que o valor desponta de relações sintáticas e de relações semânticas. As últimas é que nos interessam neste estudo, na medida em que elas cuidam da articulação fundadora de um corpo cravado na semântica discursiva.

A noção saussuriana de valor parte do domínio fechado do sentido no interior do signo, mas salta daí para examinar a propriedade de um signo de ser a contraparte de seu outro. Desse salto, emerge o valor que respalda a solidariedade entre um signo e outro. Do valor, Saussure vai a um "sistema de valores" e aponta para a prática do jogo de xadrez, comparada à língua, quando afirma: "De um lado e de outro, estamos em presença de um sistema de valores e assistimos às suas modificações. Uma partida de xadrez é como uma realização artificial daquilo que a língua nos apresenta de forma natural" (p. 104).

O sistema regrado está na definição das práticas, dos discursos, do corpo do sujeito discursivo, porque está na definição saussuriana de língua. Diz também Saussure que "mesmo fora da língua, todos os valores parecem estar regidos por esse princípio paradoxal" (p. 134) - o princípio que observa semelhanças e diferenças concomitantes entre dois termos. Lembra então o genebrino que "os valores são sempre constituídos, em primeiro lugar, por uma coisa dessemelhante, suscetível de ser trocada por outra cujo valor resta determinar; em segundo lugar por coisas semelhantes que se podem comparar com aquela cujo valor está em causa" (ibid.). 
Como herdeiros de Saussure, constatamos que a diferença, que emerge da semelhança, e que orienta a definição do valor linguístico, indica, ao analista do discurso, o que buscar em suas análises: a gramática das práticas, dos discursos, do estilo como um éthos que enuncia. Como não está sob o peso de uma semântica local ou tópica, o conceito saussuriano de valor linguístico é incorporado na descrição de mecanismos discursivos que compõem: a) o interior de um gênero, na solidariedade entre a composição, a temática e o estilo (BAKHTIN, 1988b); b) o exterior de um gênero, no exame feito da semelhança e da diferença dele com outros, do que sairá robustecido o estilo do próprio gênero.

Além disso, o princípio da semelhança e da diferença entre dois elementos coexistentes na relação trazida à tona leva o analista a descrever a presença de um discurso no outro e a presença de uma formação discursiva na outra (como negação do seu contrário), e assim por diante. O eu e o outro: a Análise do Discurso e o quadro do pensamento filosófico de Bakhtin não estão em margem oposta ao Curso de Linguística Geral. A noção saussuriana de valor linguístico favorece a ponte.

O valor na língua faz consolidar-se a forma linguística como uma rede de diferenças entre os termos, o que não é oposição entre termos positivos. O valor advém da articulação entre diferenças, o que não é mera oposição. A língua (analisável no plano das ideias e no plano das imagens acústicas) para Saussure confirma-se como um sistema de valores puros (p. 161), o que dá base à noção de sincronia e forja critérios para a análise discursiva.

Podemos topicalizar: a) A língua é um sistema de valores intrinsecamente dinâmicos, pois cada valor linguístico é dependente de outros. b) A interdependência dos sons e das ideias funda a unicidade formal. c) A rejeição de qualquer possibilidade de apreender uma unidade da língua de modo autônomo aponta para procedimentos afins na análise de discursos e práticas. d) A articulação entre os elementos do sistema no plano das ideias favorece as condições de emergência de uma semântica estruturada, sustento do corpo que enuncia.

A semelhança e a diferença entre dois termos, iluminados pela relação que os reúne, remonta à interdependência desses termos. Cabem então outras perguntas: $\mathrm{O}$ conceito do signo árvore limita-se ao interior desse mesmo signo? Diante da solidariedade de um signo com outro, que marca a semelhança e a diferença entre eles, ou diante do eixo de substituições possíveis, que também se baseiam na semelhança e na diferença entre os termos, o signo está destinado aos limites de um único significado para árvore - vegetal lenhoso? Ou, correlacionado necessariamente a outros, que estão no repertório linguístico e na memória discursiva e interdiscursiva, árvore implica vegetal lenhoso, na medida em que esse significado é estabelecido conforme a negação de um oposto, como diagrama que representa os constituintes de uma oração, etc.? Certamente o valor desliza entre um significado e outro no sistema da língua.

O linguista olha para o signo no espaço de interação com outros, para depreender o significado que é uno e que é duplo, e que talvez por isso acolha a nomeação de significação. Isso ampara o analista do discurso, que entende o interdiscurso como o que precede o discurso (MAINGUENEAU, 2005). O mesmo analista promove a descrição dos mecanismos que compõem um enunciado e compreende que não se restringirá, na sua prática, ao exame do interior desse enunciado. Ao contrário, o analista procura identificar os recursos segundo os quais cada discurso introduz em si o outro. O outro virá no modo da semelhança, da qual desponta a diferença, para que se crie o efeito de 
identidade, base da enunciação semantizada. Esses movimentos têm como ponto de partida o legado do $C L G$, obra que pensa o signo e seu derredor, na medida em que o derredor do signo sustenta o conceito de valor, e o valor organiza o pensamento.

Esse derredor, assim levado em conta, afasta o saussurismo de um imanentismo visto por alguns como um caso limite de um idealismo abstrato, de um solipsismo linguístico que isola a língua da sociedade. Também permite que se entenda o jogo das oposições linguísticas (jogo das diferenças sem termos positivos) como contribuição para o estudo das humanidades. Buscar no interior de um corpus uma identidade confundida com a noção de valor viabiliza a própria noção de identidade como alguma coisa não fechada em si. A partir daí deparamo-nos com outra questão: Da identidade do signo, podemos chegar à identidade do falante, apreensível no interior da língua e do discurso?

\section{Língua, fala e sujeito falante}

Contemplar essa questão convida ao retorno à dicotomia língua/fala e cobra observação sobre modos de recepção do $C L G$. Saussure não institui no interior da língua a função, o papel do falante, numa fala que teria potencial para sistematizar-se, embora, no Curso, encontremos um ponto de vista de um falante a subsidiar as relações sígnicas. O signo, convencional na relação estabelecida entre imagem acústica e conceito que o compõe (SAUSSURE, 1970), acaba por validar, em si, a presença de um sujeito, seja por meio da memória do som (imagem acústica/ significante), seja por meio da interpretação conceitual (significado). Mas a distinção entre o sistema virtual (língua) e o ato de realização individual (fala) mantém no Curso limites bem precisos. O sujeito falante realizaria seus atos de fala de acordo com sua vontade, do que resultaria uma diversidade incontornável para o sintagma frasal - as frases (p. 123), por meio das quais o falante se exprimiria conforme sua "liberdade individual" (p. 145), o que afastaria a própria frase do sistema de relações que constitui a língua.

"A frase é o tipo por excelência de sintagma. Mas ela pertence à fala e não à língua" (p. 144), afirma Saussure, que acrescenta esta ressalva: "Cumpre reconhecer, porém, que no domínio do sintagma não há limite categórico entre o fato da língua, testemunho de uso coletivo, e o fato de fala, que depende da liberdade individual" (p. 145). Antes disso, o genebrino, que afirmara que se a frase fosse "coisa exclusiva da fala, não poderia nunca passar por unidade linguística" (p. 123), fez esta pergunta: "Até que ponto pertence a frase à língua?" (ibid.). Saussure avalia como uma falta a "diversidade que domina" as frases (ibid.), e a ausência de qualquer coisa comum a elas chama de algo surpreendente: "Se nos representamos o conjunto de frases suscetíveis de serem pronunciadas, seu caráter mais surpreendente é o de não se assemelharem absolutamente entre si" (ibid.). Saussure sugere certa perplexidade teórica diante da propriedade de diversificação da frase.

Benveniste (1995) refunda a perspectiva de Saussure sobre a natureza da frase. Para esse linguista, que acolhe a dicotomia saussuriana língua/fala sob o crivo da teoria da enunciação, a fala, como ato enunciativo, confirma-se não como "leve, livre e solta", mas sistematicamente organizada no âmago da própria língua.

Benveniste (1989, p. 82) propôs a passagem do virtual (língua) ao realizado (fala), por meio da enunciação: "A enunciação é este colocar em funcionamento a língua por um ato individual de utilização". Para o falante, Benveniste reserva o papel de quem se 
apropria da língua e de quem se institui como enunciador ao enunciar: "O ato individual de apropriação da língua introduz aquele que fala em sua fala. Este é um dado constitutivo da enunciação" (idem, p. 84) - ao que acrescenta: "A presença do locutor em sua enunciação faz com que cada instância de discurso constitua um centro de referência interno" (idem; ibid.). A presença do sujeito falante logo em seguida é lembrada como bipartida: "É primeiramente a emergência dos índices de pessoa (a relação eu-tu) que não se produz senão na e pela enunciação: o termo eu denotando o indivíduo que profere a enunciação, e o termo tu, o indivíduo que aí está presente como alocutário" (idem, ibid.).

Para Benveniste, a fala se projeta regrada: não importa a diversidade incontornável das frases, mas é justamente devido a essa diversidade que se esboça a natureza regrada do discurso, já que cada frase tem seu centro dêitico, a enunciação, radicada numa constância formal. "Desde o momento em que o enunciador se serve da língua para influenciar de algum modo o comportamento do alocutário, ele dispõe para este fim de um aparelho de funções" (idem, p. 86). Aparelho, como conjunto de peças, um aparelho de jantar, por exemplo, lembra um sistema; diz respeito a um todo que, desdobrado em partes, sustenta-se nelas, que, por sua vez, são articuladas em relação a ele. A articulação está orientada pela função de cada aparelho inteiro e de cada peça no interior dele. A enunciação como um "aparelho de funções" traz à luz as três categorias que a constituem (pessoa, tempo e espaço). São categorias que, advindas do centro de referência enunciativo, desdobram-se conforme sistemas, tal como foi desenvolvido por Fiorin (1996). Na semântica discursiva, a articulação entre percursos temáticos e entre componentes da figuratividade instala o corpo do ator da enunciação, que imprime nas figuras e temas um julgamento predicativo também articulado. Chegamos a isso porque entendemos, com Benveniste (1995, p. 139), que a frase (unidade da fala, para Saussure) "é unidade do discurso".

A diversidade de usos da língua, homologada à diversidade das frases, é assim referida por Benveniste (idem, ibid.): "um inventário dos empregos de uma frase não poderia nem mesmo começar", diferentemente dos fonemas, dos morfemas, e até das palavras (lexemas) - unidades, que, como diz, "existem em número finito" - ao que completa: "As frases, não." (idem, ibid.). Por fim, temos esse postulado: "A frase pertence bem ao discurso. É por aí mesmo que se pode defini-la: a frase é unidade do discurso" (idem, ibid.), a que segue: "A frase é uma unidade, na medida em que é um segmento do discurso" (idem, ibid.).

Os estudos linguísticos avançam, e chegamos ao sintagma textual, não como uma soma de frases, mas, conforme o princípio de articulação entre as partes de um todo e deste com elas; o texto é examinado como unidade; é um todo organizado de sentido. $\mathrm{O}$ sentido global de um texto é o resultado da combinação sintagmática entre suas partes, a qual é geradora de associações semânticas (bem como é gerada por estas). Reencontra-se a constância entre as frases na composição do enunciado, que é engendrado em torno do $e u$, do aqui e do agora - o conjunto de categorias, que, formadoras da enunciação, fazem a mediação entre língua e fala. $\mathrm{O}$ enunciado, ao qual está pressuposta sintaticamente a enunciação que se enuncia, também encarna semanticamente o enunciador, e isso de modo regulado.

No circuito do discurso, avançamos, junto à AD (Análise do Discurso) francesa, para o interdiscurso (MAINGUENEAU, 2005). Par a par com o interdiscurso, homologável à noção de um contexto que não é envelope do texto porque é constituinte 
dele, vem a noção de formação discursiva. Com Pêcheux, a formação discursiva entra para o âmbito da AD francesa: essa noção tinha sido apresentada por Foucault (1969, p. 53) como um conjunto de enunciados identificáveis por seguirem um mesmo sistema de regras historicamente determinadas. A formação discursiva é postulada por Pêcheux (PÊCHEUX; FUCHS, 1975, p. 11) como "um conjunto de enunciados que, componente de determinada formação ideológica, determina o que pode e deve ser dito (articulado sob a forma de um sermão, de uma exposição, de um programa, etc.), a partir de posição dada em uma conjuntura"; por isso diriam respeito a "condições de produção específicas" (idem, ibid.).

Com Maingueneau (1997, p. 51), ela é apresentada como um "sistema de regras que funda a unidade de um conjunto de enunciados sócio-historicamente circunscritos"; é também ressaltada na própria "inconsistência interior", essa inconsistência entendida como um efeito de interdiscurso (MAINGUENEAU, 2014, p. 87); é um "sistema de restrições invisíveis, transversal a unidades tópicas" (idem, p. 81). Com Fiorin (1988, p. 32), do lado da semiótica discursiva, é apresentada como um "conjunto de temas e de figuras que materializa uma dada visão de mundo".

As formulações sobre a formação discursiva, considerada uma unidade do interdiscurso, são tributárias do princípio de articulação entre as unidades no interior da língua, do que emerge a relevância do valor, que ilumina a relação entre os termos, não os termos em si. Vamos a um caso exemplar.

\section{Entre a língua e a fala: o valor do signo "bandeirante"}

No CLG (1970), fica proposto que o conteúdo de uma palavra somente é verdadeiramente determinado pelo concurso do que existe fora dela. Fazendo parte de um sistema, ela está revestida não só de uma significação como também, e sobretudo, de um valor, e isso é coisa muito diferente (p. 134). O valor constrói a unidade linguística.

Se o valor constrói a unidade linguística, ela não é concreta, ela não é dada desde o começo, como acontece com a Química. "Podem-se estudar a natureza e a composição do bicromato de potássio sem duvidar um só instante de que seja um objeto bem definido" (p. 123). Então, se ecoava a pergunta: "Qual é a unidade da fala?" - para a qual obtivemos a resposta: "É a frase", segundo Benveniste. "É o texto", segundo os avanços dos estudos linguísticos - vinha, ao lado daquela pergunta esta outra: "Podemos deslocar o princípio do valor linguístico para uma unidade do discurso, como uma figura - a figura de um ator do enunciado?".

Há um caso exemplar que responde a essas questões. É o caso de um signo que se compõe no interior de um enunciado e na relação entre um enunciado e outro: a figura do bandeirante, personagem da história paulista. O bandeirante, o ator de quem se fala em dois enunciados postos em confronto, pode ser examinado como o que firma no interior do discurso o interdiscurso. Isso é possível, já que o analista contempla não a figura em si, mas a relação que ela estabelece com o todo, o enunciado de onde foi extraída.

O enunciado primeiramente é levado em conta, na medida em que se compõe segundo uma organização interna, estabelecida entre suas partes; depois, na correlação com o que é externo a ele, o interdiscurso que o atravessa. No interdiscurso, de que desponta a figura referida, o ator participante da história de um povo, deslizam duas formações discursivas - o bandeirante é uma figura que emerge tematizada ora no papel 
de herói mítico (FD1 - formação discursiva 1, aquela do poema "O caçador de esmeraldas", de Olavo Bilac), ora no papel do ator social que avançou pelo interior do estado de São Paulo em performance próxima de um protagonismo interesseiro - num ensaio historiográfico (FD 2 - formação discursiva 2). Cada formação discursiva concretiza um ponto de vista sobre o ator do enunciado.

A figura do bandeirante, examinada no interior do texto e na comparação de um texto com outro se reveste de um valor que the confere uma identidade, o que pensamos a partir do valor linguístico postulado por Saussure. Firmado no interior do discurso, o interdiscurso oferece formas opostas para o corpo desse ator do enunciado. $\mathrm{O}$ bandeirante é apreciado eticamente e reconstruído esteticamente conforme dois polos semânticos opostos, certamente - mas de pressuposição recíproca. Olhar desse modo para a figura desse personagem da história paulista é método analítico tributário da noção relativa aos dois eixos da linguagem que organizam nosso pensamento: o paradigma e o sintagma. $\mathrm{O}$ agenciamento semântico do eixo paradigmático (memória virtual - relação entre unidades in absentia) exercido no eixo sintagmático (encadeamento e combinação de unidades relacionadas in praesentia - o sintagma textual, o enunciado, para os estudos discursivos) implica este fato: o poema $O$ caçador de esmeraldas retém para a figura do bandeirante o que o ensaio historiográfico retira dela - e vice-versa. O contraste entre ambos os conjuntos de temas e figuras, instalados no poema e no ensaio, assenta-se nas duas formações discursivas aproximadas no cotejo analítico. A figura do bandeirante, entendida como arena de conflito social, como signo ideológico, conforme previu Bakhtin/Voloshinov (1988a), emparelha-se ao alerta feito por Saussure de que, diferentemente do que fazem os químicos, não operamos com unidades dadas, prontas desde o começo como o bicromato de potássio. A partir de pontos de vista diferentes, a obra Marxismo e Filosofia da Linguagem (1988a) e o CLG apresentam-se como não excludentes na relação estabelecida entre elas.

Assim como não é procedimento esperado pelo método saussuriano de análise linguística - que alguma unidade seja levada em conta em si mesma, o que implica uma comparação feita jamais entre dois termos positivos - para a análise do bandeirante do poema cumpre examinar a correlação com o bandeirante do ensaio. Cada um se compõe como negação do seu contrário. Mais que isso, é preciso examinar como cada uma dessas unidades - cada um desses signos feitos figuras encarnadas no corpo de um ator do enunciado (personagem) - traz em si o todo que ela condensa: um todo que remonta a práticas relativas à historiografia e ao discurso literário.

Da identidade de uma unidade da língua saltamos, pois, para a identidade de uma figura do enunciado, um signo, bandeirante, tornado ator do enunciado; o bandeirante, que só existe na relação estabelecida com o produtor dos textos, o enunciador do poema e o enunciador do ensaio. O enunciador pressuposto ao poema e ao ensaio, para enunciarse, delega ao narrador a voz que institui o ator do enunciado, o bandeirante, que, no poema, brada e se contorce; no ensaio, é figura de baixa densidade estésica ou de baixa conotação sensível como compete ao gênero ensaio historiográfico (aqui o bandeirante é o ele de quem se fala). Os bandeirantes 1 e 2 - cada um deles está fletido conforme as coerções de cada esfera da comunicação: a literatura, entendida como discurso literário, e a historiografia, entendida como discurso historiográfico. 
Da parte vamos ao todo, como princípio sustentado desde o $C L G$ e que perpassa o pensamento do dinamarquês Hjelmslev (2003), que herdou o pensamento científico de Saussure. Um estudioso da obra de Hjelmslev, Semir Badir, realça esse princípio de que da parte se vai ao todo, de que a unidade contém a totalidade, tal qual firmado na linguística estrutural definida pelo dinamarquês. Assim afirma Badir (2000, p. 98): "Num poema, uma estrofe pode constituir um corpus a partir do qual se deduz um esquema linguístico: num esquema, as variantes são ligadas entre si (apenas uma característica é suficiente para explicar todas elas) [o que confirma a noção de isotopia]".

Do lado da AD francófona, temos esta declaração de Maingueneau (2014, p. 78), que vai ao encontro do princípio de que a unidade contém a totalidade: temos aí mais uma voz teórica que deslinda, par a par com o $C L G$, critérios para a seleção e tratamento de um corpus de análise discursiva, que é interdiscursiva necessariamente:

Nada impede de trabalhar sobre um texto singular. Um corpus pode ser constituído tão somente de um único texto [...] se sua seleção resulta de um questionamento associado a uma problemática. Nesse caso, o pesquisador considera que esse texto, pela maneira segundo a qual ele emerge num certo lugar, é uma espécie de "carrefour" [lugar de intersecção], que dá acesso a uma rede de fenômenos julgados pertinentes para compreender uma configuração mais vasta. (MAINGUENEAU, 2014, p. 78).

\section{Notas finais}

Um poema de Olavo Bilac narra a história de Fernão Dias Paes Leme, bandeirante caracterizado como o caçador de esmeraldas. É lá apresentado o protagonista, num percurso que vai da entrada no sertão, aos delírios em que ele vê esmeraldas em toda parte, ou vê a natureza metamorfoseada na pedra preciosa. Entremeada aos delírios, chega a morte do caçador de pedras preciosas. Destacamos dois excertos:

1. A entrada do bandeirante no sertão:

\section{O CAÇADOR DE ESMERALDAS}

(Episódio da epopeia sertanista no XVII Século)

Foi em março, ao findar das chuvas, quase à entrada

Do outono, quando a terra, em sede requeimada,

Bebera longamente as águas da estação,

- Que, em bandeira, buscando esmeraldas e prata,

À frente dos peões filhos da rude mata,

Fernão Dias Paes Leme entrou pelo sertão.

(BILAC, 1968, p. 73).

2. O delírio do bandeirante antes de sua morte:

Verdes, os astros no alto abrem-se em verdes chamas;

Verdes, na verde mata, embalam-se as ramas;

E flores verdes no ar brandamente se movem; 
Chispam verdes fuzis riscando o céu sombrio;

Em esmeraldas flui a água verde do rio,

E do céu, todo verde, as esmeraldas chovem...

(BILAC, 1968, p. 81)

O ensaio historiográfico da Professora Maria Isaura Pereira de Queiroz comenta trabalhos de história tanto anteriores como concomitantes ao século XX: são estudos voltados para a questão da formação da "raça de gigantes", relativa a uma elite paulista detentora da concentração do capital econômico na sociedade de então. Era, segundo a exposição feita pela autora, a elite cúmplice na criação de mitos de uma paulistanidade heroica. Nesse entremeio, a historiadora faz vir à tona a figura do bandeirante. Do ensaio historiográfico, apresentamos estes excertos:

Ufanismo paulista: vicissitudes de um imaginário

1. A apresentação do problema ligado à imagem do bandeirante:

Cada coletividade tende a ter seus símbolos próprios, dotados de um significado específico, com a função de perpetuar determinados valores. Ser paulista, manifestação de uma coletividade geograficamente localizada, se exprime através de uma figura mítica, a do bandeirante: feitos do passado definem a este, quando conquistou para a Coroa portuguesa o imenso interior brasileiro, caracterizando-se então pela audácia, pelo desejo imoderado de conquista, pelo sentimento de independência, pela vocação de mando, pela lealdade - "raça de gigantes" disse já um historiador. Tem-se a impressão de que a imagem sempre existiu, desde os antigos tempos em que as bandeiras percorriam os sertões em busca do ouro.

Descobrir que tal na verdade não ocorreu e que, pelo contrário, seu aparecimento está perfeitamente localizado não só no espaço, mas também no tempo constitui uma primeira surpresa. (QUEIROZ, 1992, p. 79)

2. O símbolo do bandeirante em outros níveis sociais.

O outro nível aludido por Queiroz é a Revolução de 1932. A historiadora referese ao círculo de trabalhos historiográficos que trataram do bandeirante e lembra que,

[...] para que tal símbolo ultrapassasse o âmbito intelectual restrito em que surgira, foram muito importantes os meios de comunicação de massa já existentes - jornais, revistas, cartazes, aos quais se somavam outros novos, como o alto-falante e o rádio, que alcançavam um público muito mais vasto (1992, p. 85).

\section{Complementa:}

O espirito bandeirante era constantemente invocado para reforçar o entusiasmo da população, lembrando que a iniciativa, a eficiência, a bravura que toda a coletividade estava demonstrando eram a prova da filiação ilustre. O Caçador de Esmeraldas, o Anhanguera eram invocados a todo instante como deuses lares que levariam os descendentes à vitória $(1992$, p. 85).

A ver, por meio da análise, como virá aos nossos olhos o valor discursivo do signo linguístico bandeirante, no trânsito entre a língua e a fala, entre o enunciado e a 
enunciação; o valor da figura do bandeirante no intervalo entre as práticas evocadas pela literatura e pela historiografia. A articulação entre um e outro bandeirante remeterá não a uma distinção entre termos positivos, o que implicaria levar em conta tão somente a relação entre um único significante para dois significados. Desse modo, o bandeirante emergiria como entidade em si. Se o $C L G$ postula a língua como forma, não substância, a forma está no corpo do bandeirante, o ator discursivo do enunciado, e, concomitantemente, está nos mecanismos de engendramento do ator da enunciação.

Nesse caso do bandeirante, uma estabilidade formal inclui a isotopia de papéis temáticos e configurativos do ator do enunciado e do ator da enunciação. Para o "eu lírico", Fernão Dias Paes é o corpo mítico, que junta às conquistas realizadas em vida os meandros da morte vividos na experiência sensível. Para a ensaísta, o conjunto da performance do bandeirante é outro. Tanto lá como cá, o corpo se firma como estrutura, para definir o ator, tanto do enunciado, como da enunciação, conforme um sistema semântico. Essa perspectiva analítica, favorecida por estudos relativos a uma estilística discursiva (DISCINI, 2015), apresenta um viés que emerge em consonância com o que pensa Saussure sobre a língua como sistema. O fato de Saussure ter "descoberto" a língua no interior da dicotomia língua/fala oferece recursos para que se descreva o estilo não de modo "realista", mas com o olhar voltado ao corpo do ator que enuncia: um corpo sistematizado na semântica do discurso e do interdiscurso.

\section{REFERÊNCIAS}

BADIR, S. Hjelmslev. Paris: Les Belles Lettres, 2000.

BAKHTIN, M. M. (V. N. Volochinov). Marxismo e filosofia da linguagem: problemas fundamentais do método sociológico na ciência da linguagem. Tradução de Michel de Lahud e Yara Frateschi Vieira. Prefácio de Roman Jakobson. Apresentação de Marina Yaguello. 4. ed. São Paulo: Hucitec, 1988a.

BAKHTIN, M. Questões de literatura e de estética. A teoria do romance. Tradução de Aurora Fornoni Bernardini et al. São Paulo: Hucitec, 1988b.

BENVENISTE, E. Problemas de Linguística Geral II. Tradução de Eduardo Guimarães et al. Campinas: Pontes, 1989.

Problemas de Linguística Geral I. Tradução de Maria da Glória Novak e Maria Luisa Neri. 4. ed. Campinas: Pontes, 1995.

BILAC, O. Poesia. Rio de Janeiro: Livraria Agir Editora, 1968.

DISCINI, N. Corpo e estilo. São Paulo: Contexto/ FAPESP, 2015.

FIORIN, J. L. Linguagem e ideologia. São Paulo: Ática, 1988. Ática, 1996.

. As astúcias da enunciação. As categorias de pessoa, espaço e tempo. São Paulo:

FOUCAULT, M. L'Archeologie du savoir. Paris : Gallimard, 1969.

GREIMAS, A. J.; COURTÉS, J. Dicionário de Semiótica. Tradução de Alceu Dias Lima et al. São Paulo: Contexto, 2008.

HJELMSLEV, L. Prolegômenos a uma teoria da linguagem. 2. ed. Tradução de J. Teixeira Coelho Neto. São Paulo: Perspectiva, 2003. 
MAINGUENEAU, D. Os termos-chave da Análise do Discurso. Tradução de Maria Adelaide P. P. Coelho da Silva. Lisboa: Gradiva, 1997.

. Gênese dos discursos. Tradução de Sírio Possenti. São Paulo: Criar, 2005.

. Discours et analyse du discours. Introduction. Paris: Armand Colin, 2014.

PÊCHEUX, M.; FUCHS C. Mise au point et perspectives à propos de l'analyse automatique du discours. Langages, $9^{\mathrm{e}}$ année, n. 37. Analyse du discours, langue et idéologies, sous la direction de Michel Pêcheux, 1975. p. 7-80. Disponível em: $<\mathrm{http}: / / w w w . p e r s e e . f r / d o c / l g g e \_0458-726 x \_1975 \_n u m \_9 \_37 \_2612>$. Acesso em: 21 jul. 2016.

QUEIROZ, M. I. P. de. Ufanismo paulista: vicissitudes de um imaginário. In: Revista USP, Publicação trimestral da Superintendência de Comunicação Social (SCS/USP), n. 13, p. 79-87, 1992.

SAUSSURE, F. Curso de linguística geral. 2. ed. Tradução de Antônio Chelini, José Paulo Paes e Izidoro Blikstein. São Paulo: Cultrix, 1970.

Recebido em: 30/09/2016

Aprovado em: 29/11/2016 